\title{
Comments on the incidence and natural history of gastric and duodenal ulcer
}

\author{
C. N. Pulvertaft \\ County Hospital, York
}

\section{Incidence}

Studies of the incidence of peptic ulceration can be no more than a mass of dull statistics, or, on the other hand, can raise fascinating problems-which are largely unanswered. For example, there have been several studies showing that there is a higher frequency of duodenal ulcers in the North of this island as compared to the South; and again there is good evidence the incidence of new duodenal ulcer cases in this country has decreased in recent years. There is, or probably more accurately was, a higher incidence in urban than rural areas. The reasons for these differences are unknown.

One of the major problems in incidence studies is that of diagnosis, or definition, of an ulcer subject. All methods of diagnosis, clinical, radiological, gastroscopic, laparotomy and even autopsy are open to criticism; the latter, for example, depends, to no small extent, on the zeal of the observer. It is extremely difficult, I believe, to obtain $100 \%$ accuracy in diagnosis, and $I$ am sure there are many men who have been labelled as having duodenal ulcers on inadequate evidence, but, on the other hand, there are some in whom the diagnosis has been missed.

It would be easy to devote all the time available to discussing this problem, but I must limit my comments to two points.

Firstly, I would like to stress the importance, particularly in the case of acute ulcers, of examining patients during a period of actual symptoms, not after first being treated at home, then waiting for an out-patient appointment, with a further delay for a barium meal.

Secondly, a passing comment on the radiological evidence of healing in duodenal ulcer. This is, in my opinion, mainly guess-work, and unless one has demonstrated an ulcer crater it is, by and large, a waste of time, and unnecessary irradiation of the patient.

\section{Acute perforation}

One of the simplest methods is the study of acute perforations, and several population sur- veys, in this country and Australia (Pulvertaft, 1959; Billington, $1960 \mathrm{a}, \mathrm{b})$ have shown that acute perforations represent some $11 \%$ of the chronic ulcer population; in a recent study Sanders (Sanders, 1967) has suggested that it is possible to use perforation incidence as an indication of total ulcer numbers.

In the 1950s there were three studies reporting acute perforation, one from Glasgow (Jamieson, 1955), one from Aberdeen (Weir, 1960), and one from York (Pulvertaft, 1959).

It was possible to compare:

(1) The total perforation rate $/ 100,000$ population for 1952-53 in Glasgow and York, which were:

\begin{tabular}{lcc}
\hline & Men & Women \\
\hline Glasgow & $32 \cdot 6$ & $3 \cdot 2$ \\
York & $26 \cdot 6$ & $2 \cdot 8$ \\
\hline
\end{tabular}

(2) Perforated duodenal and gastric ulcers (men) in Aberdeen for 1946-57.

The rate per/1000 for duodenal ulcers was twice as high in Aberdeen $(0.86)$ as in York $(0 \cdot 41)$. Perforated gastric ulcers were, however, less common in Aberdeen than York.

Watkinson (1958), in a National Autopsy Survey, also noted a lower autopsy incidence in the South as compared to the North of England.

Sanders (1967) reporting a low incidence in Oxford, suggested that these differences might be partly explained on ABO blood group distribution. He showed that the percentage of the population with blood group $O$ was $53 \%$ in Glasgow and $51 \%$ in Aberdeen, compared to $47 \%$ in York and $44.5 \%$ in Oxford.

\section{Changes in ulcer incidence in recent years}

During our survey in York (1952-57) (Pulvertaft, 1959) it was noted that the number of new cases of male duodenal ulcer diagnosed per year in the City of York was falling, but this was not happening in the surrounding country area. 
This study was continued until 1963 , and the findings are summarized in Fig. 1. The main point of interest is the dramatic decline for male duodenal ulcers in the City of York. This has not occurred in the rural area, nor for women in either area. There has been a slight fall off for gastric ulcers in York, but this is small: no appreciable change has occurred for rural men, or for women, in either area.

In the early years significantly more male duodenal ulcers occurred in the town than the country, but this difference has almost entirely disappeared by $1961-63$.

(a)

(b)

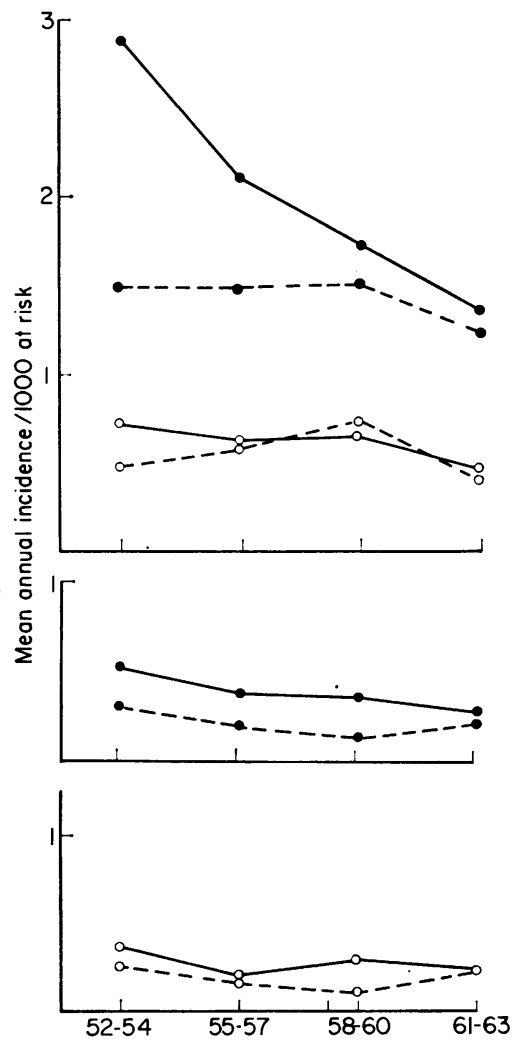

FIG. 1. Incidence of gastric (b) and duodenal (a) ulcers (excluding pyloric antrum) 1952-63 (inclusive). The 12 years have been divided into four periods of 3 years each: the figures represent the mean annual incidence/1000 at risk for each of the four periods. Combined active gastric and duodenal ulcers, at time of diagnosis, are included in both gastric and duodenal ulcers. Men (York); $---O$, men (country); $\mathrm{O}-\mathrm{O}$, women (York); O---O, women (country).

In the period 1952-56 both gastric and duodenal ulcers were significantly $(P<0.01)$ more common in the semi-skilled and unskilled workers than in the professional and semi-professional classes in the city. As far as can be said the decline which has occurred is equally distributed $c$ throughout the social classes.

This decline, in men, has occurred in all age $\stackrel{\vec{S}}{\stackrel{D}{S}}$ groups, though possibly more pronounced in those over 55 (Fig. 2). No appreciable change has taken place in women of any age.

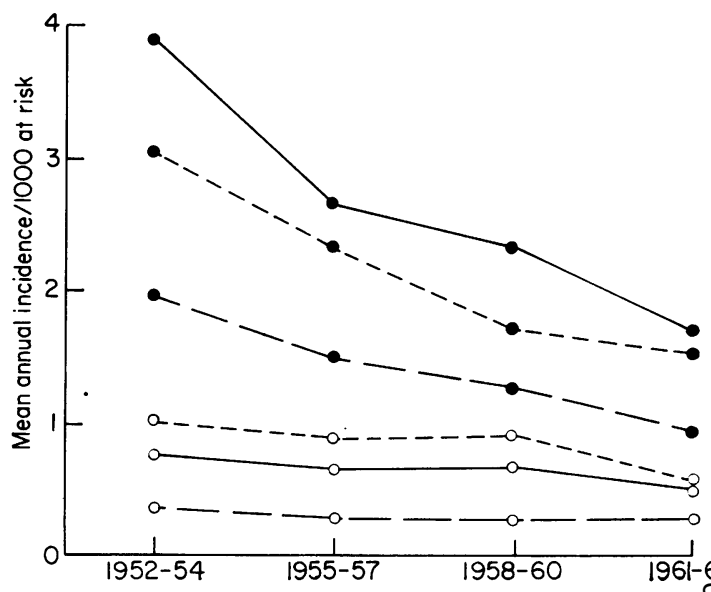

FIG. 2. Incidence of duodenal ulcers in men (O) and women (O), in the City of York in relation to age and time (1952-63). $-\frac{}{15}$, aged 55 and over ; - - - -, aged 35-54; - - - aged 15-34.

It was possible that in the early years there was a pool of uninvestigated and undiagnosed ulcer patients, resulting in an apparent higher incidence. The frequency of subjects with histories of over 5 years, was therefore, compared with that of those less than 2 years, in three age groups (Fig. 3). It is clear that the fall off has occurred in both groups but that, if anything, it is more marked in men with short histories.

These changes were reflected in the acute perforation rates (York) - both the total perforation rate and the 'new' duodenal ulcer rate show a progressive decrease (Fig. 4).

This might have been a local phenomenon, $\frac{T}{0}$ but unpublished data supplied by the Registrar General, from the $10 \%$ Hospital In-Patient En- N quiry, for acute perforations in England and $N$ Wales, for 1956-61, showed (Fig. 5), that the $\mathcal{N}$ changes in York were merely part of a national trend.

Recently Sanders (1967) reported similar findings from Oxford, the incidence of perforated peptic ulcers having fallen from 14 to $7 / 100,000$ between 1957 and 1963, the decrease being due to duodenal and not gastric ulcers. 

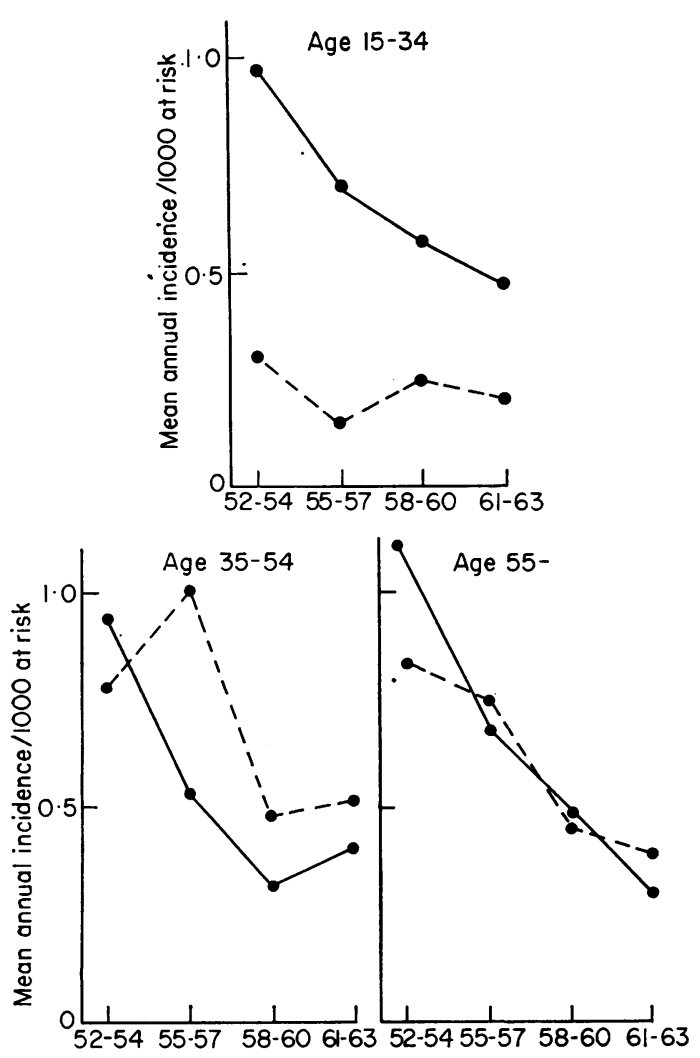

Fig. 3. Comparative incidence of patients with short histories ( $<2$ years, - -$)$ and long histories ( $>5$ years, - - - ) for three age groups. Men-duodenal ulcersCity of York

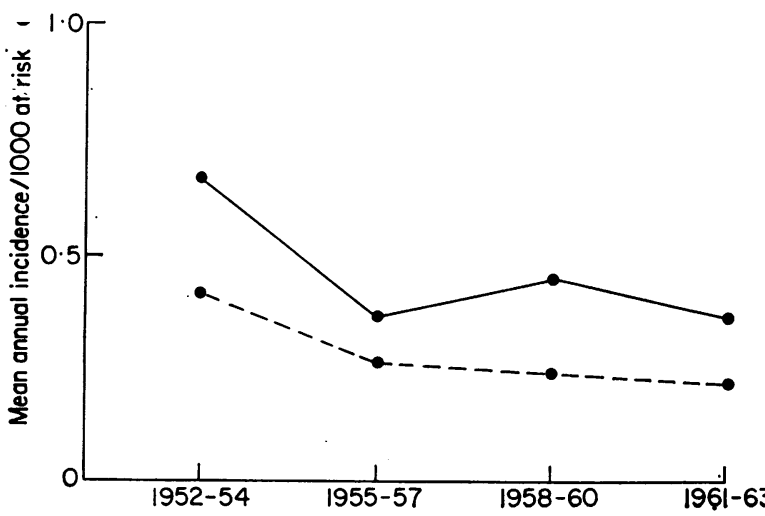

FIG. 4. Incidence of total male perforations (old and new cases, gastric ulcers and duodenal ulcers, - - ) and of patients presenting in the first instance as perforated duodenal ulcers ( - - - , including prepyloric perforations)-City of York.
The differing incidences in the city and country gave rise to much speculation-the superficial explanation that this was the outcome of increased stress of life in York, or that the labouring classes suffered more stress than the professional and semi-professional classes was unconvincing.

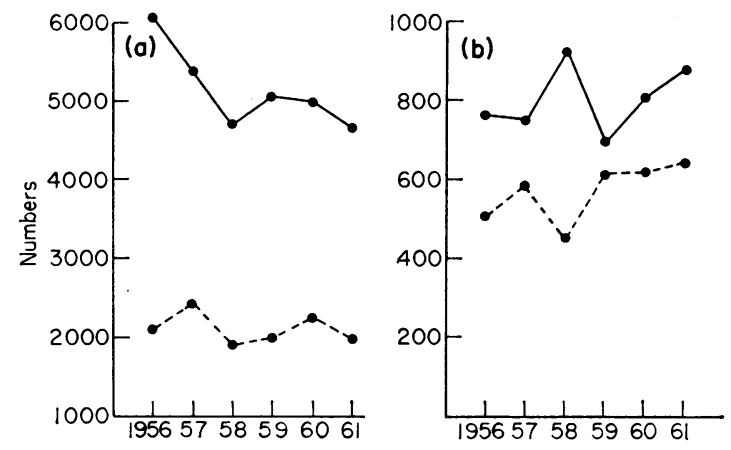

FIG. 5. Estimated acute perforations for England and Wales from Ministry of Health $10 \%$ In-Patient Enquiry. (a) Men, (b) women. _ - duodenal ulcers; - - -, gastric ulcers.

Natural history of duodenal ulcer

In presenting these data I must apologize for the fact that, although this study has not been published, it is somewhat out-of-date, as I have not been able to analyse it since 1963 , and owing to the limited time I can only present certain aspects of this study and I am, moreover, excluding gastric ulcers.

The material represents practically every case of ulcer diagnosed during the period 1952-56. Subjects having an emergency gastrectomy for haemorrhage at the time of diagnosis are not included. We regarded a postal questionnaire, in this instance, as being unsatisfactory and made no attempt to follow subjects who left the district -in all, we have lost 5-6\% due to this causethey are, however, included up to the time of leaving York.

The series consists of 694 men and 205 women.

It is important to stress that these patients represent a complete cross-section of the ulcer population, moreover, it also represents all aspects, and biases, of treatment-the opinion of physicians, surgeons, and general practitioners. During the course of follow-up little or no attempt has been made to influence an individual doctor in his treatment of the patient. Roughly $80 \%$ of both men and women were first seen as out-patients, of this $80 \%$ approximately $30 \%$ were first treated by physicians, $30 \%$ by surgeons, and $20 \%$ referred by their own doctor. 
Each patient has been assessed in the same way as our post-operative series at yearly intervals, being graded as Grade 1 or 2 if they have had no, or only slight, symptoms, during the year, as 'satisfactory' (Grade 3) if they have had symptoms not entirely controlled by diet or medicaments, but which are not severe and have not necessitated loss of work, and as bad results (Grade 4 and 5) if they have had severe clinical symptoms, haemorrhage, perforation, elective surgery, or lost more than 2 weeks' work in the year.

The overall assessment for the first 6 years following diagnosis, expressed as percentages of the original number for men, is shown in Fig. 6. There was a progressive decrease in the number of good results, and an increase in bad results with the passage of time. Women (Fig. 7) follow a similar pattern.

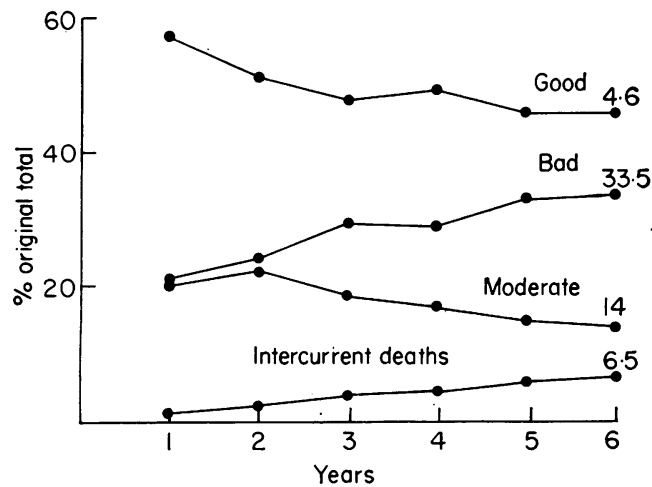

Fig. 6. Six-year follow-up, 649 male duodenal ulcers.

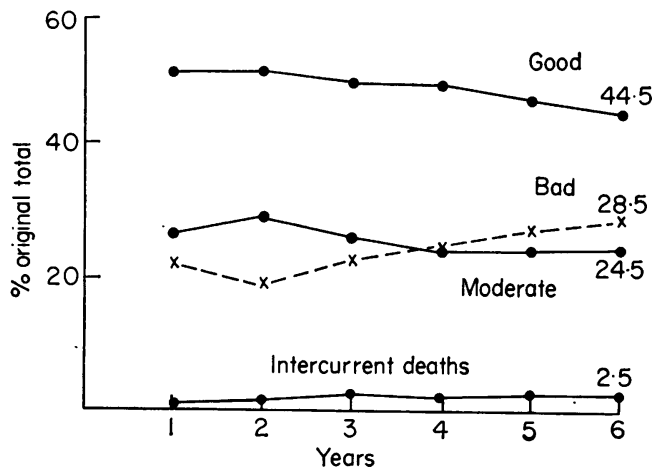

Fig. 7. Six-year follow-up, 205 female duodenal ulcers.

The cause of bad results, each year, is shown in Fig. 8. On average some $7 \%$ of men and $9 \%$ of women experienced severe clinical symptoms; and $2.7 \%$ men and $2.5 \%$ women had a haemor- rhage-either haematemesis or melaena. Rather more men than women had acute perforations$0.8 \%$ against $0.3 \%$; these perforations were evenly spread through the 6 years of observation. Elective surgery was rather more common in men than women, especially in the first 3 years. During the 6 years $27 \%$ men and $19 \%$ of women required surgery. This difference may be due to the fact that the results of surgery are better in men than women.

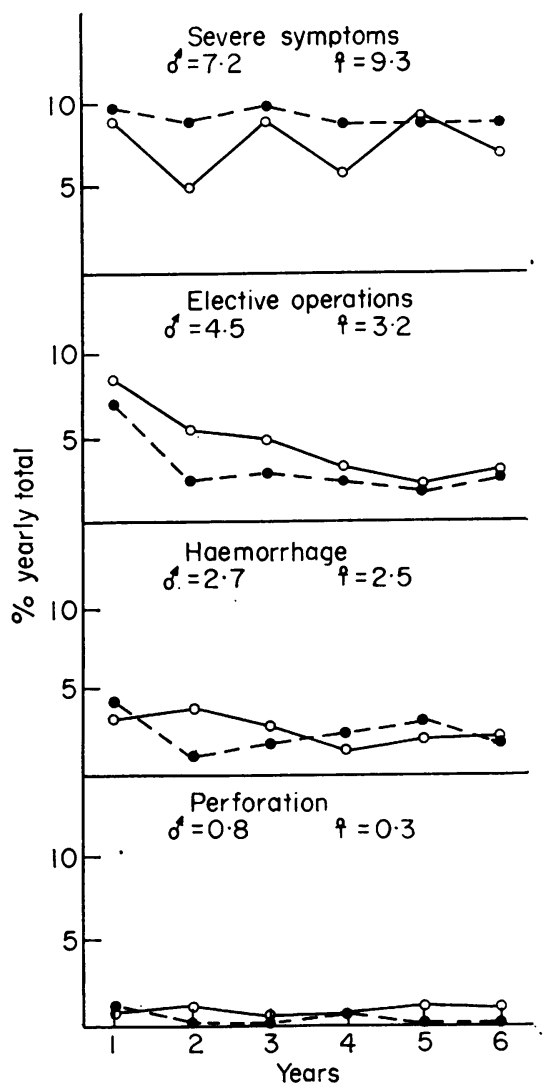

Fig. 8. Causes of bad results. O, Women; men.

Factors influencing prognosis

These factors are all so interrelated that it would require a much larger number of patients to attempt to separate them with accuracy. The o observations that follow, therefore, must be regarded more as estimates than exact findings and are based on the 10-year period of follow-up rather than the 6 years as previously considered.

These figures have been calculated from the man-years of follow-up-a method that is open to criticism-and are based on 1000 man-years of medical follow-up, or roughly 100 men being 
seen for 10 years. It is an attempt to determine the various risks for each individual, and, therefore, no account has been taken of second or third haemorrhages, or perforations, in any individual.

Age and risks of haemorrhage or perforation: In subjects first seen on account of clinical symptoms, as distinct from haemorrhage or perforation, the risks of haemorrhage rise with increasing age from 11.9 in women aged $<30$ at diagnosis to 31.7 for those aged 70 ; there is a high risk (14.5) for young men but after the age of 30 the risk increases with age- -4.3 for $30-40$, increasing to 26.9 for those aged over 60 (Fig. 9).

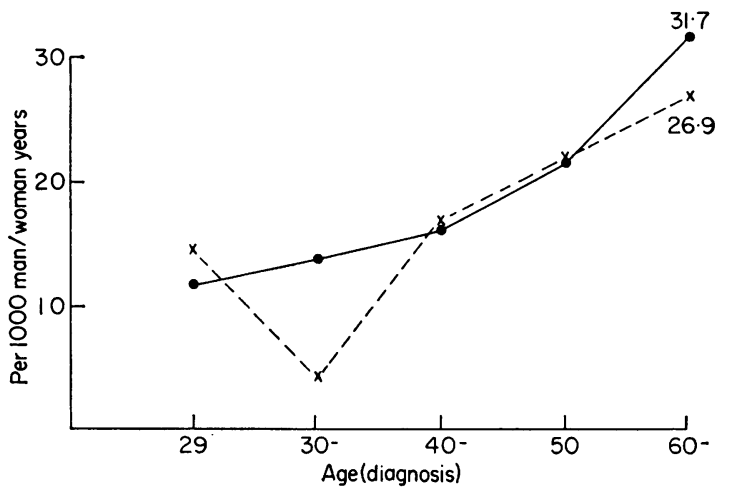

Fig. 9. Haemorrhage and age, duodenal ulcer estimates. Ten-year follow-up presenting with clinical symptoms. , Women; X, men.

Acute perforations follow a similar course. Again a high risk in young men $(7.2$ aged $<30)$ falling to $2.9(30-40)$ and rising to 10.8 for $>60$. In women the risks are smaller except in the $>60$ when it rises to $15 \cdot 8$ - but this is probably inaccurate owing to the small number of women years available for analysis (Fig. 10).

Presenting symptoms and risk of complications: Age and haemorrhage are related; therefore, in estimating the risk of haemorrhage or perforation in relation to initial symptoms the series has been divided into two age groupsabove and below 50 .

\section{Risk of haemorrhage}

If 100 men aged $<50$ at diagnosis presenting with clinical symptoms lived 10 years it is estimated that eleven would have one or more haemorrhage (Table 1); above 50 the risk would rise to twenty-four. The risks for women are very similar, thirteen and twenty-four, respectively.
TABLE 1

Risk of haemorrhage: 10-year follow-up, duodenal ulcer estimates for 1000 man years

\begin{tabular}{lcccccc}
\hline & \multicolumn{4}{c}{ Age } \\
\cline { 2 - 4 } Presentation & \multicolumn{2}{c}{ Men } & & \multicolumn{2}{c}{ Women } \\
\cline { 2 - 3 } \cline { 5 - 7 } & $<49$ & $>50$ & & $<49$ & $>50$ \\
\hline Clinical symptoms & 11 & 24 & & 13 & 24 \\
Haemorrhage & 75 & 64 & & 30 & 52 \\
Perforation & 13 & 15 & & - \\
\hline
\end{tabular}

If, however, haemorrhage was the initial symptom, the risk rises to seventy-five for men aged $<50$ and to sixty-four for over 50 (the figure of seventy-five is probably too high owing to the small number of man-years). For women, the respective risks are thirty and fifty-two.

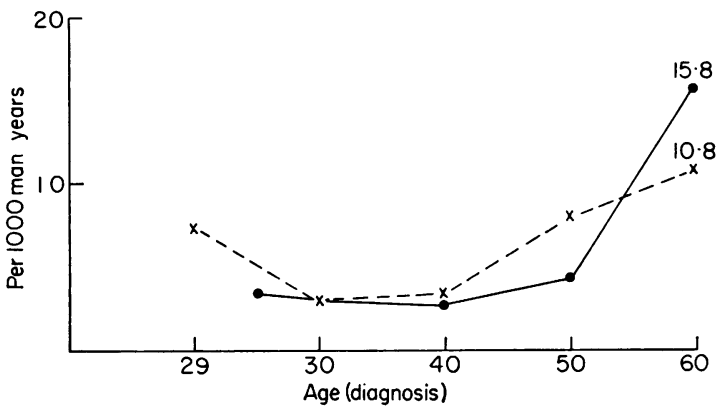

Fig. 10. Perforation and age, duodenal ulcer estimates. Ten-year follow-up presenting clinical symptoms. , Women; $\mathrm{X}$, men.

The risk for men presenting as acute perforation is similar to those with clinical symptoms; no estimate can be hazarded for women with acute perforations owing to the small number available.

TABLE 2

Risk of perforation: 10-year follow-up, duodenal ulcer estimates for 1000 man years

\begin{tabular}{lrrrrr}
\hline & \multicolumn{4}{c}{ Age } \\
\cline { 2 - 3 } & \multicolumn{2}{c}{ Men } & & \multicolumn{2}{c}{ Women } \\
\cline { 2 - 3 } \cline { 5 - 6 } & $<49$ & $>50$ & & $<49$ & $>50$ \\
\hline Clinical symptoms & 4 & 9 & & 3 & 7 \\
Haemorrhage & 7 & 3 & & - & - \\
Perforation & 15 & 13 & & - & - \\
\hline
\end{tabular}

Risk of acute perforation

There appears to be less relationship between perforation and age than was observed for haemorrhage, although (Table 2) it does seem to 
be more common in the older age-group of subjects presenting with clinical symptoms (men and women), the risk being four per 100 men living 10 years when diagnosed younger than 50 , and nine when aged $>50$; the figures for women are three and seven, respectively.

In men presenting with haemorrhage, the overall risk (all ages) is no higher than for the clinical symptom group; however, the risk rises considerably if the presenting symptom is perforationthat is, to fifteen and thirteen for the age group $<50$ and $>50$.

These estimated risks, however, do not give a full picture as some patients, particularly those with no previous indigestion, presenting as acute emergencies, do very well and have no further trouble. Therefore, to get the picture in perspective, it is necessary to consider the number of patients who remain well and symptom-free, or almost symptom-free (Grades 1 and 2) for the 6 years of complete follow-up. Excluding subjects dying of intercurrent disease or leaving the district then only $16 \%$ of men presenting with clinical symptoms will be graded as ' 1 ' throughout the period, against $24 \%$ presenting with haemorrhage and $37 \%$ with acute perforation.
Gastric ulcers, pyloric stenosis and pulmonary tuberculosis

It is difficult to present accurate figures for the risks of such complications but during the course of this study thirteen patients developed a gastric ulcer, ten pyloric stenosis and three pulmonary tuberculosis.

\section{References}

Billington, B.P. (1960a) The Australian gastric ulcer change; further observations. Med. J. Aust. ii, 19.

Billington, B.P. (1960b) Gastric ulcer: Age, sex, and a curious retrogression. Aust. Ann. Med. 9, 111.

JAMIESON, R. (1955) Acute perforated peptic ulcer. Frequency and incidence in the West of Scotland. Brit. med.J. ii, 222.

Pulvertaft, C.N. (1959) Peptic ulcer in town and country. Brit. J. prev. soc. Med. 13, 131.

SANDERS, R. (1967) Incidence of perforated duodenal and gastric ulcer in Oxford, Gut, 8, 58.

Watkinson, G. (1958) The autopsy incidence of chronic peptic ulceration, a national and regional survey of 20,000 examinations performed in Leeds, England, between 1930 and 1949 and in nine towns in England and Scotland in 1956. Schweiz. Z. Path. 21, 405.

WeIR, R.D. (1960) Perforated peptic ulcer in North-East Scotland. Scot. med. J. 5, 257. 